
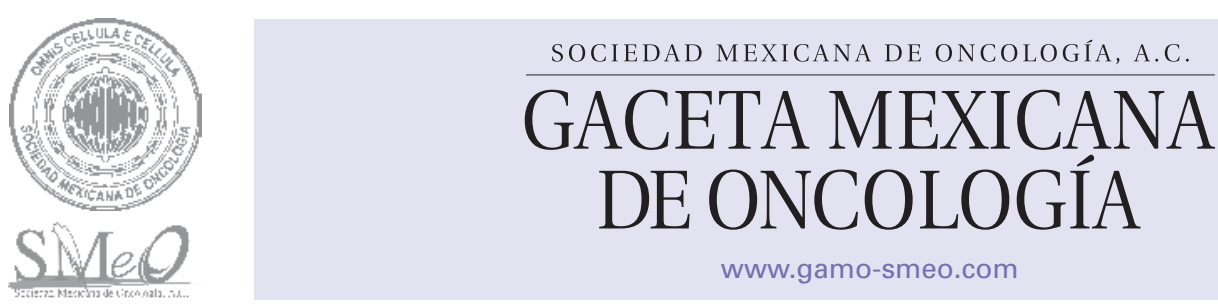

ARTÍCULO ORIGINAL

\title{
Conceptos básicos de genética clínica para la práctica oncológica
}

\section{Clara Ibet Juárez-Vázquez ${ }^{1, *}$, Ricardo Alejandro Lara-Aguilar ${ }^{1}$, Francisco Javier Ochoa-Carrillo ${ }^{2}$ y Herbert García-Castillo ${ }^{1}$}

${ }^{1}$ Fundación Vida en Genoma A.C., 2Instituto Nacional de Cancerología y Hospital Ángeles del Pedregal, Ciudad de México, México

Recibido el 10 de diciembre de 2016; aceptado el 25 de febrero de 2017

Disponible en Internet el 14 de julio de 2017

\section{PALABRAS CLAVE}

Conceptos de genética; Términos de genética; Asesoramiento genético;

Cáncer hereditario
Resumen Los cánceres hereditarios son frecuentes en la consulta de oncología. Se estima que del 5 al 10\% de todas las neoplasias diagnosticadas corresponden a cáncer hereditario. Se requiere de un estudio cuidadoso de la historia familiar y conocimiento de los principios básicos de genética para abordar este tipo de pacientes. El objetivo de este artículo es ofrecer estos conceptos como una herramienta útil en la práctica clínica de la consulta oncológica, con ejemplos prácticos, así como justificar por qué la especialidad de genética debe ser parte del equipo multidisciplinario en pacientes con sospecha de una condición oncológica hereditaria. (creativecommons.org/licenses/by-nc-nd/4.0/).

*E-mail para correspondencia: clarajuarez@lifeingenomics.com (C.I. Juárez-Vázquez) 


\section{INTRODUCCIÓN: PRINCIPIOS DE LA HERENCIA}

Cada rasgo que identificó Mendel en las plantas de guisantes, como forma, color, tamaño, etc., corresponde a la expresión de un gen diferente. El fenotipo se refiere a las características que observamos (morfológicas, fisiológicas o bioquímicas), como el color de los ojos, mientras que el genotipo es la constitución genética cuya expresión e interacción con el medio ambiente permite el fenotipo. Como ejemplo podemos mencionar el color de los ojos, que corresponde al fenotipo; el genotipo se refiere a las variantes de cada gen que influyen en la determinación de esta característica.

La palabra gen se define como un fragmento o secuencia de ADN específica que determina una característica ${ }^{1,2}$. El gen es la unidad fundamental de la herencia ${ }^{3}$. Las diferentes versiones de cada gen se denominan alelos, es decir, son las formas alternativas de un gen. Por ejemplo, el gen EYCL3 es uno de los genes que determina el color de los ojos en los humanos ${ }^{4}$, y existen dos alelos para este gen, uno para el color azul de los ojos y otro para el color café.

Todos los genes tienen una posición específica dentro de un cromosoma; esta ubicación se conoce como locus ${ }^{1}$. El gen EYCL3 está en 15q11.2, que se traduciría como cromosoma 15, brazo largo (q), banda 11.2. Dicho locus puede estar ocupado por el alelo para el color café o azul de los ojos ${ }^{4}$.

La estructura básica de un gen está conformada por regiones de ADN de tamaño variable que codifican aminoácidos específicos en la proteína, llamados exones, mientras que aquellas regiones en los genes que no codifican ningún aminoácido se denominan intrones ${ }^{5}$ (Fig. 1).

\section{HOMOCIGOTO Y HETEROCIGOTO: ALELOS IGUALES Y DIFERENTES}

Cuando los dos alelos de un locus son iguales, se denominan homocigotos y cuando son diferentes uno del otro, se llaman heterocigotos. En el ejemplo del color de los ojos, el alelo del color café (C) domina sobre el color azul (a). Así, cuando un par de alelos diferentes (heterocigotos) están presentes $(\mathrm{Ca})$, sólo se observa el rasgo físico codificado por el alelo dominante, es decir, ojos de color café; por el contrario, las personas de ojos azules serían homocigotas para el alelo a (aa).

Cabe señalar que lo anterior se cumple siempre que haya una combinación específica de alelos de EYCL3 y otros genes. El color de los ojos es un rasgo poligénico en el que influyen varios genes que interactúan con el gen EYCL3.

\section{EJEMPLO APLICADO EN LA ONCOLOGÍA}

\section{Citocromo CYP2D6}

El citocromo P450 es una familia de enzimas encargadas de metabolizar ciertos fármacos; por ejemplo, la enzima producto del gen CYP2D6 que metaboliza gran parte del tamoxifeno para convertirlo a su metabolito activo, el endoxifeno. La mayoría de personas metabolizan el tamoxifeno normalmente, pero los homocigotos para el alelo 4 (CYP2D6*4) CYP2D644) manifiestan el fenotipo metabolizador lento; por lo tanto, el tamoxifeno se metaboliza muy lento a endoxifeno, ocasionando la ineficacia del tratamiento. Estos pacientes son candidatos a inhibidores de aromatasa como letrozol, en lugar de tamoxifeno. Es de esperar que heterocigotos con el genotipo CYP2D6*1/CYP2D6*4 manifiesten el fenotipo metabolizador intermedio y tengan reducidos los niveles de endoxifeno, implicando ineficacia clínica. En población mexicana se ha encontrado una frecuencia del $3.1 \%$ de metabolizadores lentos para CYP2D6 (i.e. CYP2D6*4/E CYP2D6*4) y un $20.7 \%$ de metabolizadores intermedios, heterocigotos para CYP2D6 (i.e. CYP2D6*1/CYP2D6*4). ${ }^{6}$

El citocromo P450 es un ejemplo de un gen que sigue un patrón de herencia mendeliano donde se expresan ambos alelos en estado heterocigoto, es decir, que es un gen con patrón de herencia codominante. Actualmente se están realizando estudios con gran número de pacientes para determinar si este estudio farmacogenético se debe realizar a todos los pacientes en la práctica clínica rutinaria ${ }^{7}$.

\section{TIPOS DE HERENCIA}

La especie humana tiene 23 cromosomas, los cuales se cla sifican en autosomas (par 1 al 22) que son idénticos entre ambos sexos, y cromosomas sexuales (par 23: XX [femenino] o XY [masculino]) que designan el sexo. Por tal motivo, una enfermedad autosómica implica que el gen que produce la enfermedad esté presente en los autosomas y ambos sexos suelen estar clínicamente afectados; en las enfermedades ligadas a X, como la hemofilia, el gen que produce la enfer:medad está en el cromosoma sexual $X$ y afecta predominantemente a los varones ${ }^{1}$.

Las enfermedades producidas por un solo gen en un locus determinado se denominan monogénicas y siguen un patrón de herencia mendeliano. Una enfermedad autosómica dominante se manifiesta cuando un cromosoma porta un alelo mutado a pesar de tener un alelo normal en el otro cromo soma. Por otro lado, la herencia autosómica recesiva se observa cuando ambos cromosomas presentan el alelo mutado; sólo los individuos homocigotos presentan la enfermedad ${ }^{3}$.

\section{PENETRANCIA Y EXPRESIVIDAD}

La penetrancia se define como el porcentaje de individuos con un genotipo específico que expresa el fenotipo esperado. Cuando el genotipo no produce el fenotipo esperado, se denomina penetrancia incompleta ${ }^{1}$. Otro concepto relacionado es la expresividad, la cual se define como el nivel de expresión de una característica determinada por un gen. La expresividad variable representa el espectro de expresión de un genotipo específico. Tanto la penetrancia incompleta como la expresividad variable se deben a efectos de la interacción entre factores genéticos y ambientales que pueden alterar o suprimir parcial o totalmente el efecto de un gen determinado, por lo que la sola presencia de un gen alterado no garantiza su expresión. El fenotipo es resultado de un genotipo que se expresa en un ambiente específico, es decir, que cada genotipo puede producir varios fenotipos diferentes según las condiciones ambientales e interacciones con otros genes en las que ocurre el desarrollo ${ }^{1}$. 


\section{Ejemplo aplicado en la oncología}

El gen $B R C A$ es un gen supresor de tumor responsable del $60 \%$ de los casos de cáncer de mama y ovario hereditario. Este gen se encarga de la reparación de rupturas de doble cadena del ADN y se hereda de manera autosómica dominante, es decir, que hay un $50 \%$ de riesgo de que la descendencia herede el gen del padre afectado. Sin embargo, aunque se tenga un alelo afectado, se requiere que el otro alelo se dañe a lo largo de la vida para que produzca cáncer, lo que se conoce como teoría de Knudson o del doble golpe (se explicará más adelante).

La penetrancia de este gen es alta pero incompleta; el 41-90\% de personas que heredan una mutación presentan el cáncer a lo largo de la vida ${ }^{8}$. La expresividad es variable: algunas personas presentan cáncer de mama, otras, cáncer de ovario y en menor proporción en otros órganos como páncreas, trompas de falopio y peritoneo, y en hombres se presenta con más frecuencia cáncer de próstata y mama. Cabe mencionar que también habrá pacientes que presenten más de un tumor a lo largo de su vida y que hay riesgo de cáncer contralateral $(64 \%)$ y cáncer de ovario $(44 \%)$ después de un primer cáncer de mama.

El riesgo de cáncer en portadores de mutaciones $B R C A$ aumenta con la edad, debido a la penetrancia incompleta y a la expresividad variable; el desarrollo y comienzo del cáncer no pueden predecirse de manera precisa ${ }^{3}$.

\section{MUTACIONES Y POLIMORFISMOS}

Los cambios en la secuencia de ADN que son inexplicables por la recombinación de los genes, se llaman mutaciones. Las mutaciones pueden ser alteraciones en el número o es: tructura de los cromosomas o deberse a cambios en la secuencia de ADN (por ejemplo, mutaciones puntuales, cambios o sustituciones de una base por otra) ${ }^{2}$.

Las mutaciones son fuente de la evolución, ya que pro porcionan la materia prima para que ésta se lleve a cabo. Sin las mutaciones, los genes sólo existirían en una sola

Tabla 1. Principales tipos de mutaciones ${ }^{1,5,15-18}$

\begin{tabular}{|c|c|}
\hline Tipo de mutación & Definición \\
\hline \multirow{2}{*}{$\begin{array}{l}\text { Sustitución } \\
\text { de una base }\end{array}$} & Cambia la base nitrogenada de un solo nucleótido del ADN original por otra distinta. \\
\hline & Ejemplo: g.45576A>C, cambia una adenina por una citosina en la posición genómica 45576 del gen \\
\hline \multirow[t]{2}{*}{ Inserción } & Ganancia de uno o más nucleótidos agregados a la secuencia de ADN original. \\
\hline & $\begin{array}{l}\text { Ejemplo: g.5756_5757insAGG, inserción de los nucleótidos AGG entre las posiciones } 5756 \text { y } 5757 \text {, } \\
\text { generando un aumento de tres bases en la secuencia del gen }\end{array}$ \\
\hline \multirow[t]{2}{*}{ Deleción } & Eliminación de uno o más nucleótidos en la secuencia de ADN. \\
\hline & Ejemplo: g.120_123del, se produce una pérdida de los nucleótidos 120 al 123 de la secuencia del gen. \\
\hline \multirow[t]{2}{*}{$\begin{array}{l}\text { Cambio del marco } \\
\text { de lectura }\end{array}$} & $\begin{array}{l}\text { Inserción o deleción de un número (no múltiplo de } 3 \text { ) de nucleótidos en el ADN que afecta la } \\
\text { traducción original de la proteína. }\end{array}$ \\
\hline & $\begin{array}{l}\text { Ejemplo: c. } 288 \text { 289dupCC (p.Arg97Profs*23) los nucleótidos } 288 \text { y } 289 \text { están duplicados, resultando } \\
\text { en el cambio de Arginina en la posición } 97 \text { por una prolina, y crea un nuevo marco de lectura y un } \\
\text { codón de paro en la posición } 23 \text {. }\end{array}$ \\
\hline
\end{tabular}

Expansión por repetición de trinucleótidos

Cromosómica

Genómica

De sentido equivocado

Sin sentido Secuencia repetida de tres nucleótidos
potencialmente el tamaño de un gen.

Ejemplo: c.53GCA[80], incrementa el número de repetidos GCA (80 veces repetidos los tres nucleótidos) en la secuencia codificante del gen

Alteración del número o estructura de uno o más cromosomas, afectando a muchos genes que generan cambios fenotípicos importantes.

Ejemplo: 47, XY, +21 , trisomía 21, presencia de un cromosoma 21 extra

Alteración del número haploide de la especie, ocasionando poliploidía.

Ejemplo: 69,XXX, triploidía, presencia de 3n, complemento haploide adicional

Cambio del codón del aminoácido silvestre por otro distinto alterando la función de la proteína.

Ejemplo: c.4576A>C; p.Leu126Arg, el cambio de adenina por citosina provoca que cambie el aminoácido leucina silvestre por arginina.

Cambio del codón del aminoácido silvestre por un codón de paro ocasionando la terminación prematura de la proteína dejándola sin función.

Ejemplo: c.4576A>X; p.Leu126*, el cambio de adenina por otro nucleótido provoca que cambie el aminoácido leucina por un codón de terminación de la proteína

Silenciosa
Cambio de un codón codificante por otro sinónimo, por lo que no se altera la secuencia de aminoácidos de la proteína.

Ejemplo: c.4576A>C; p.Leu126=, a pesar del cambio de adenina por citosina en la secuencia del gen, el nuevo codón codifica para el mismo aminoácido leucina. 


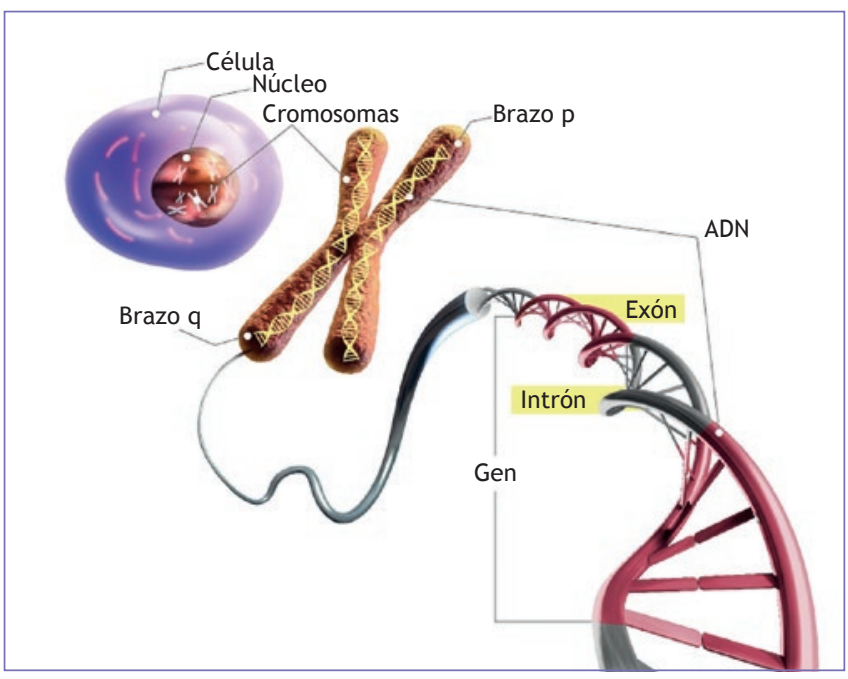

Figura 1. Estructura y localización de un gen.

forma y los organismos no podrían evolucionar y adaptarse a los cambios ambientales².

Los polimorfismos son variantes genéticas presentes en más del $1 \%$ de la población, mientras que las mutaciones están presentes en menos del $1 \%$. Las variantes de un solo nucleótido se llaman Single Nucleotide Polymorphism y se distinguen de las mutaciones puntuales por su frecuencia en la población ${ }^{3}$.

Las mutaciones pueden originarse en cualquier célula y en cualquier etapa del ciclo celular. Si la mutación se produce en células somáticas (cualquier célula, excepto los gametos), estas células producirán células hijas iguales a ella, por lo que la mutación sólo será detectable en las células descendientes de la célula original en la que se inició la mutación ${ }^{2}$. Si la mutación se produce en células germinales (ocurre en alguno de los gametos: óvulo o espermatozoide), es posible que sus efectos se expresen en la descendencia ${ }^{2}$ debido a que la mutación está presente en todas las células del cuerpo del individuo ${ }^{3}$. En la tabla 1 se ilustran los diferentes tipos de mutaciones, con ejemplos de la nomenclatura en cada caso.

\section{GENES DE CÁNCER}

Los principales reguladores del ciclo celular (división, reparación y muerte célular) son un grupo específico de genes que al estar mutados propician en gran medida el desarrollo de cáncer ${ }^{3}$.

En general, las mutaciones que ocurren en los genes que promueven el crecimiento y división de la célula son dominantes, ya que sólo se requiere que una sola copia del gen esté mutada para producir su efecto; estos genes se conocen como oncogenes. En células normales las formas no mutadas de los oncogenes, se conocen como protooncogenes, al mutar se transforman en oncogenes contribuyendo al desarrollo del cáncer ${ }^{1}$.

Los genes supresores de tumor en estado silvestre (normal) controlan la progresión del ciclo celular y pueden bloquear la división en células que contienen daños en el ADN; en cambio, los genes supresores de tumor mutados, son incapaces de realizar su función propiciando que la célula dañada se divida y prolifere sin control; para este efecto se requiere que ambas copias del gen estén mutadas (mutación recesiva). De esta manera, un individuo puede heredar una copia defectuosa del gen (estado heterocigoto) y no desarrollar la enfermedad, debido a que el otro alelo es silvestre. Sin embargo, los individuos heterocigotos están predispuestos a presentar cáncer porque la inactivación o pérdida del alelo silvestre es lo único que se necesita para eliminar la actividad supresora del tumor, lo que se conoce como pérdida de heterocigosidad ${ }^{1}$.

Existe otro grupo de genes, llamados reparadores del $A D N$, que corrigen los errores del sistema durante la división celular, pero estos genes también sufren mutaciones, por lo que se han asociado a varios tipos de cáncer (colorrectal endometrial, gástrico) ${ }^{1}$.

\section{Ejemplo aplicado en la oncología}

Un ejemplo de oncogén es el gen KRAS. Tener mutado un protooncogén se considera de mal pronóstico. Se ha estudiado en cáncer de colon y pulmón, entre otros. En particular, si se encuentra mutado, no se recomienda dar quimioterapia con cetuximab ni panitumumab por la baja tasa de respuesta.

En cuanto a los genes supresores de tumor, están los genes reparadores de mal apareamiento de bases (por sus siglas en inglés MMR: Mismatch Repair Genes) MSH2 ye MLH1, causantes del $90 \%$ de los casos de síndrome de Lynch o también conocido como cáncer colorrectal no polipoide hereditario. Este síndrome es autosómico dominante de expresividad variable y penetrancia incompleta. El cáncer más frecuente en este síndromes es el de colon, sin embargo también existe riesgo de presentar cáncer en otros órganos como estómago, intestino delgado, endometrio, entre otros. Este cáncer suele manifestarse a los 50 años y presentarse predominantemente en colon proximal. Los pacientes con mutación en estos genes tienen riesgo del $52-82 \%{ }^{9}$ de desarrollar cáncer de colon a lo largo de la vida. Los genes MSH2 y $M L H 1$ corrigen errores de mal apareamiento durante la replicación del ADN y al estar mutados propician daños en genes ${ }^{3}$.

\section{EL CÁNCER ES UNA ENFERMEDAD GENÉTICA}

Las células normales llevan a cabo varios procesos en respuesta a señales internas y externas (estimuladoras o inhibidoras): crecen, se dividen, maduran y mueren. En una célula de cáncer algunas de estas señales son interrumpidas, haciendo que la célula prolifere a una velocidad anormalmente mayor por la pérdida de la respuesta a los mecanismos de control normal; así modifican la forma original y producen finalmente una masa celular anormal.

El cáncer surge por mutaciones en el ADN que alteran genes relacionados con la regulación de la división celular. Las radiaciones ionizantes y sustancias químicas son carcinogénicas debido a que en algunas ocasiones rompen el ADN en una o dos de sus hebras activando un oncogén. Virus como el VPH producen cáncer debido a que portan oncogenes que son capaces de inmortalizar la célula que infectan. Otros cánceres se asocian a defectos en los cromosomas, 
por ejemplo en leucemia mieloide crónica se presenta una translocación recíproca entre los cromosomas 9 y 22 que genera un gen híbrido $B C R-A B L$ con actividad oncogénica. Otros cánceres son hereditario debido a la transmisión de genes supresores de tumor mutados ${ }^{1}$.

La mayoría de los tumores tienen decenas de mutaciones puntuales en varios genes, pudiendo llegar a tener más de 200 mutaciones. El 95\% de las mutaciones son cambios puntuales. Sin embargo, muchas de estas mutaciones se consideran pasajeras (passenger mutations), no confieren una ventaja selectiva de crecimiento, mientras unas pocas son conductoras (drivers mutations), es decir, que promueven la tumorogénesis. Un tumor típico tiene 2-8 mutaciones conductoras que están relacionadas con vías de señalización que regulan procesos de destino celular, sobrevida y mantenimiento genómico ${ }^{10}$.

\section{Ejemplo aplicado en la oncología}

El retinoblastoma es una enfermedad autosómica dominante producida por la alteración en el gen supresor de tumor RB1. La hipótesis de Knudson o teoría del doble golpe (Alfred Knudson, 1971) explica la base genética de este cáncer. Knudson propuso que el retinoblastoma se debe a dos defectos genéticos diferentes y es necesario que ambos sucedan para que se desarrolle el cáncer. En los casos en que el retinoblastoma es unilateral, una sola célula sufre dos mutaciones sucesivas. En casos de retinoblastoma bilateral, ambos ojos estan predispuestos a desarrollar cáncer, Knudson propone que el paciente hereda una de las dos mutaciones necesarias para el cáncer (primer golpe), y, por lo tanto, todas las células de los ojos contienen la mutación inicial, requiriendo una segunda mutación (segundo golpe) para que se presente la enfermedad. Cabe señalar que en estos casos hereditarios también hay riesgo de otro tipo de cánceres como sarcomas, osteosarcomas y melanomas ${ }^{1}$.

\section{CLASIFICACIÓN DEL CÁNCER SEGÚN SU ORIGEN GENÉTICO}

\section{Cáncer esporádico}

El cáncer esporádico resulta de la acumulación adquirida, secuencial y no corregida de mutaciones en células somáticas. La activación de mutaciones en oncogenes y la inactivación de genes supresores de tumor probablemente sean los primeros eventos de los tumores esporádicos, además de otras mutaciones independientes en al menos 4-5 genes ${ }^{11}$. Otra característica es la edad de presentación la cual es la esperada para el tipo de cáncer en población general, por lo que generalmente no afecta a familiares y pueden existir factores de riesgo ambientales agregados ${ }^{12}$.

\section{Cáncer familiar vs. hereditario}

El cáncer familiar se presenta en varios miembros de una familia, no es posible reconocer patrones de herencia y mutaciones en común; sin embargo, existe incremento del riesgo de presentar distintos cánceres debido a la participación de factores ambientales similares ${ }^{13}$.

\section{Cáncer hereditario}

El cáncer hereditario afecta a varios miembros de una familia y es posible encontrar patrones de herencia. Generalmente se presenta en personas de menor edad a la esperada para el tipo de cáncer en población general, suelen ser cánceres más agresivos y se diagnostican por ciertas características clínicas. En los cánceres hereditarios es importante la identificación de mutaciones germinales en uno de los alelos de los genes de alta susceptibilidad a cáncer. Por ejemplo, en el cáncer de mama hereditario los genes de alta suscepti bilidad son BRCA1, BRCA2, PALB2, CHEK 2, TP53 y PTEN ${ }^{11,1}$

\section{ASESORAMIENTO GENÉTICO EN ONCOLOGÍA}

El asesoramiento genético consiste en brindar información ye orientación al caso índice y sus familiares sobre el papel de los genes y la posibilidad de que los descendientes hereden el riesgo de cáncer, además de explicar las recomendaciones internacionales sobre las estrategias de seguimiento e inclu-g so terapéuticas y quirúrgicas actualmente disponibles, así como las incertidumbres médicas y la ayuda para resolver problemas psicosociales; finalmente, se deben explicar los beneficios y limitaciones de las pruebas moleculares ${ }^{15}$.

Los riesgos de predisposición a cáncer pueden variar entre las familias debido a la intervención de otros genes mo dificadores o del estilo de vida ${ }^{15,16}$.

El asesoramiento genético es parte primordial del diag. nóstico de cáncer y en México lo realiza un médico genetista. Es necesario llevar a cabo un adecuado asesoramiento genético antes y después de indicar una prueba molecular ${ }^{1}$.

\section{CONCLUSIONES}

Se han introducido conceptos básicos en genética clínica, in cluyendo conceptos de mutaciones, polimorfismos, nociones de nomenclatura, tipos de herencia, así como algunas aplicaciones interesantes en los campos de la farmacogenética, oncogénesis, clasificación de los cánceres según su origen ỳ el asesoramiento genético, que en números posteriores se tratarán a profundidad. El conocimiento de los principios de la genética aplicados a la consulta permitirá un manejo integral del paciente y la mejor comprensión de los estudios genéticos en la práctica oncológica.

\section{AGRADECIMIENTOS}

Agradecemos a la Dra. Silvia Vidal Millán sus valiosos comentarios en la realización del presente manuscrito.

\section{BIBLIOGRAFÍA}

1. Pierce BA. Fundamentos de genética. Conceptos y relaciones. Editorial Médica Panamericana; 2011.

2. Gardner EJ. Principios de Genética. Editorial LimusaWiley; 1998.

3. Nussbaum RL. Thompson \& Thompson, Genetics in Medicine. Editorial Saunders; 2004. 
4. Eiberg $\mathrm{H}$, Mohr J. Assignment of genes coding for brown eye colour (BEY2) and brown hair colour (HCL3) on chromosome 15q. Eur J Hum Genet. 1996;4:237-41.

5. Salazar-Montes A. Biología Molecular. Fundamentos y aplicaciones en las ciencias de la salud. Editorial Mc Graw Hill; 2013.

6. Contreras AV, Monge-Cazares T, Alfaro-Ruiz L, et al. Resequencing, haplotype construction and identification of novel variants ofCYP2D6 in Mexican Mestizos. Pharmacogenomics. 2011;12:745-56.

7. Hoskins JM, Carey LA, MCLeod HL. CYP2D6 and tamoxifen: DNA matters in breast cancer. Nat Rev Cancer. 2009;9:576-86.

8. National Comprehensive Cancer Network. NCCN Clinical Practice Guidelines in Oncology: Genetic/Familial High-Risk Assessment: Breast and Ovarian, 2017. Available at: https://www.nccn.org/professionals/physician_gls/f_guidelines.asp (Accessed Jan 15, 2017).

9. National Comprehensive Cancer Network. NCCN Clinical Practice Guidelines in Oncology: Genetic/Familial High-Risk Assessment: Colorectal, 2017. Available at: https://www.nccn.org/professionals/physician_gls/f_guidelines.asp (Accessed Jan 15, 2017).

10. Vogelstein B, Papadopoulos N, Velculescu VE, Zhou S, Diaz LA Jr, Kinzler KW. Cancer genome landscapes. Science. 2013;339:1546-58.
11. Kenemans $P$, Verstraeten RA, Verheijen RHM. Oncogenic pathways in hereditary and sporadic breast cancer. Maturitas. 2004;49:34-43.

12. Clemons $M$, Goss P. Estrogen and the risk of breast cancer. N Engl J Med. 2001;344:276-85.

13. American Cancer Society. Genes and Cancer. Available at: http:// www.cancer.org/acs/groups/cid/documents/webcontent/002550-pdf.pdf .pdf (Accessed December 31, 2016).

14. ACOG Committee opinion no. 634: Hereditary cancer syndromes and risk assessment. Obstet Gynecol. 2015;125:1538-43.

15. Vidal Millán S. Cáncer de Mama Hereditario: Identificación y Elección de Pacientes para Estudio Molecular de los Genes BRCA. Cancerología? 2008;3:51-61.

16. Ochoa-Carrillo FJ, Millán SV. [Importance of genetic counseling and molecular diagnosis testing in families at high risk for cancer]. Cir Cir. 2006;74:137-42.

17. Solari JA. Genética Humana. Fundamentos y aplicaciones en Medicina Médica Panamericana, Cuarta edición; 2011.

18. Sequence Variant Nomenclature. Version 15.11. Available at: http: varnomen.hgvs.org/recommendations/protein/variant/frameshift/o (Accessed January 26, 2017). 